\title{
Multicentric pigmented Bowen's disease of the genitalia associated with carcinoma in situ of the cervix
}

\author{
CLODAGH M KING, VICTORIA M YATES, AND V K DAVE \\ From the Skin Hospital, University of Manchester School of Medicine, Manchester
}

SUMMARY A case of multicentric pigmented Bowen's disease in a 45 year old woman with a previous history of carcinoma of the cervix is described. The two conditions may have a common pathogenesis, and a preceding viral infection with herpes simplex or human papillomavirus could be of aetiological relevance. Patients with multicentric pigmented Bowen's disease may be at risk of developing other tumours of the genital tract. Treatment with carbon dioxide laser proved effective.

\section{Introduction}

Multicentric pigmented Bowen's disease is a relatively benign form of carcinoma in situ of the genitalia, which has emerged as a distinct clinical entity since its recognition by Lloyd in $1970 .{ }^{1}$ We report on a patient in whom multicentric pigmented Bowen's disease was preceded by carcinoma in situ of the cervix, and describe successful treatment of this condition by carbon dioxide laser.

\section{Case report}

A 45 year old woman presented with a one year history of increasing black pigmentation of the anogenital region associated with pruritus (fig 1). Examination showed intense pigmentation extending from the mons pubis to the natal cleft, which was macular on the clitoris, labia, and vaginal introitus but on the posterior commissure, perianal area, and natal cleft there were multiple pigmented papules coalescing to form plaques (fig 2). Multiple biopsy specimens taken from the perineum and perianal skin all showed cellular and nuclear atypia of the epidermis consistent with multicentric pigmented Bowen's disease (fig 3).

Two years previously routine cervical cytology had disclosed severe dysplasia, and a cone biopsy of the cervix confirmed the presence of carcinoma in situ. A radical hysterectomy was performed. At that time no

Address for reprints: Dr C M King, Senior Registrar in Dermatology, The Skin Hospital, University of Manchester School of Medicine, Quay Street, Manchester M3 3HL

Accepted for publication 26 March 1984 abnormality was noted on the anogenital skin. The patient had no history of herpes genitalis, condylomata acuminata, or any sexually transmitted

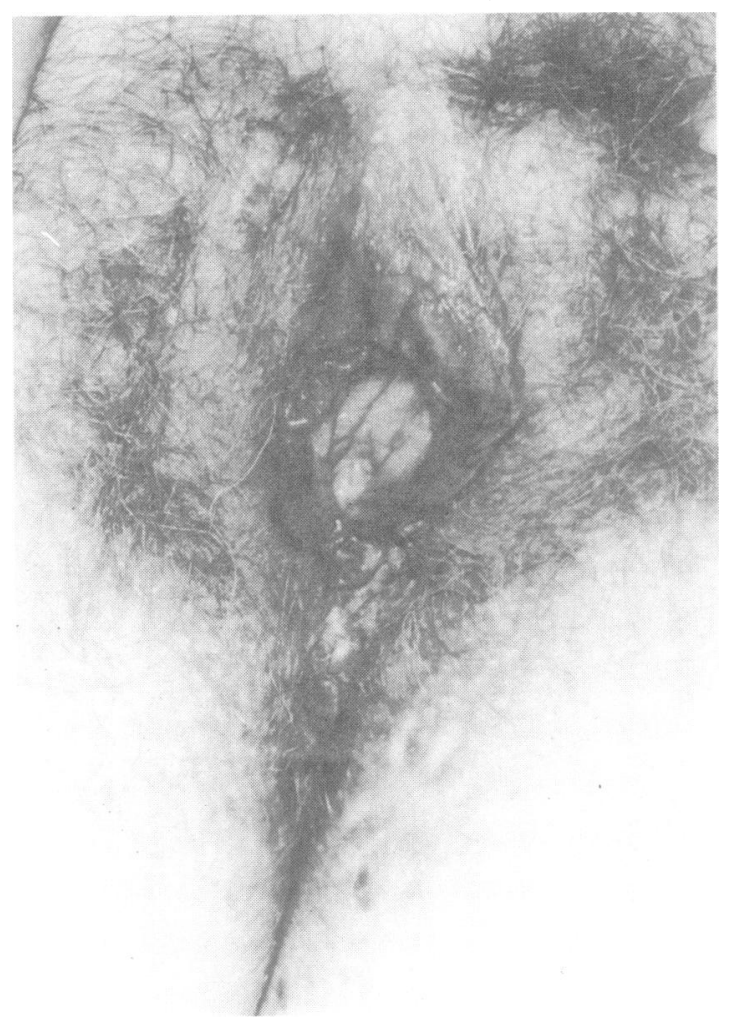

FIG 1 Extensive black macular pigmentation extending from the mons pubis to the posterior commissure. 


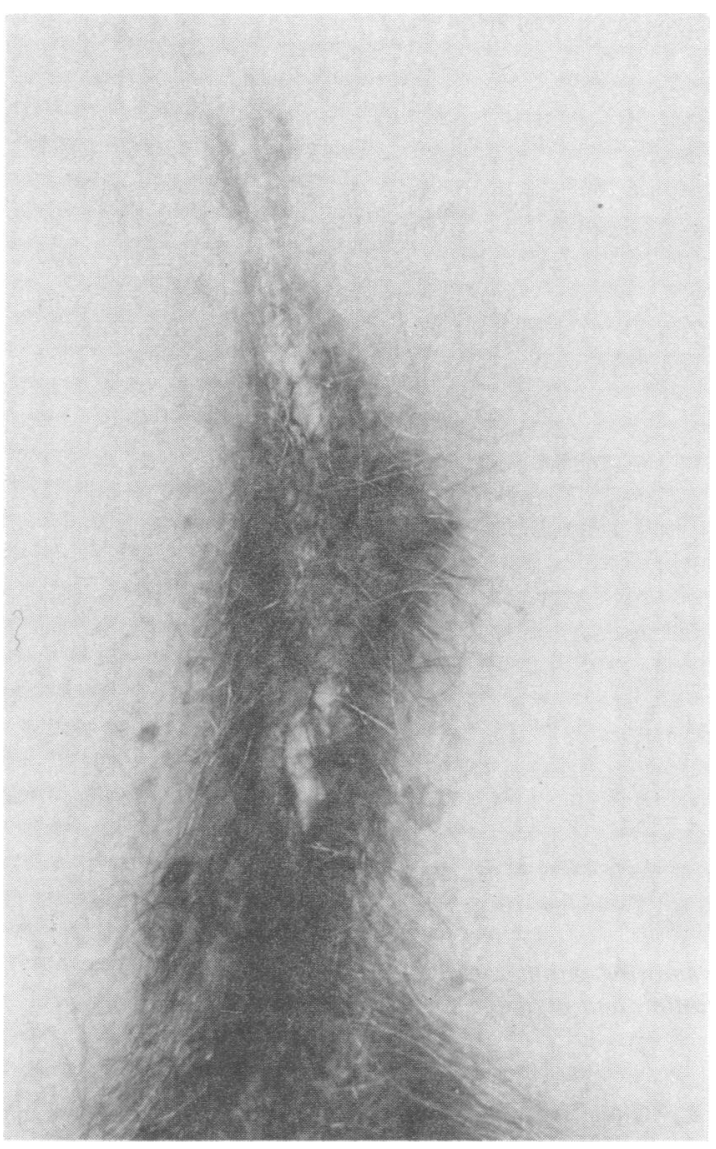

FIG 2 Darkly pigmented multicentric papules coalescing to form plaques on the perianal region and the natal cleft.

disease, or of exposure to carcinogens such as arsenic, dye phototherapy, or pelvic irradiation. The only previous medication had been the contraceptive pill, which she had taken eleven years earlier for four years. In the seven years preceding the diagnosis of carcinoma of the cervix no form of contraception, including barrier forms, had been used.

Initial treatment with 5-fluorouracil (Efudix) 2\% in fatty acid propylene glycol base (Metosyn diluent) produced some resolution of the papules but resulted in skin irritation. This was therefore discontinued, and carbon dioxide laser vaporisation was started on the perianal area. She received four treatments at intervals of three to six months over a total period of 14 months. The affected skin was treated to a depth of 3-4 $\mathrm{mm}$. This produced only slight discomfort and resulted in clearing of the lesions with minimal scarring, and there has been no evidence of recurrence in the treated areas to date.

\section{Discussion}

Multicentric pigmented Bowen's disease has also been described as Bowenoid papulosis and referred to in men as pigmented penile papules and in women as reversible vulvar atypia. It characteristically presents in young adults, but has also been described in patients over $60 .^{2}$ The initial lesions are multicentric papules, which are often irregular in outline and may be flat topped and shiny or verrucous. They occur most commonly on the penile shaft or the labia majora and may coalesce to form velvety plaques over a wide area of the anogenital skin. Lesions range in colour from reddish-brown to black, and may be pruritic. Both light and electron microscopy show features similar to classic Bowen's disease but with milder degrees of cellular atypia and occasionally perinuclear vacuole formation in the epidermis, as seen in condyloma acuminatum. ${ }^{3}$

Multicentric pigmented Bowen's disease usually behaves in a benign fashion, and in many instances spontancous regression has been described in both sexes. ${ }^{45}$ Hirai et $a l^{6}{ }^{6}$ however, reported a case that progressed to squamous cell carcinoma, and De Villez and Stevens reported progression to classic Bowen's disease. ${ }^{7}$ As the malignant potential of multicentric pigmented Bowen's disease is therefore uncertain, some form of conservative ablative treatment is advised. Vulvectomy or amputation of the penis are unnecessary. ${ }^{3}$ Cryotherapy has been used successfully, ${ }^{8}$ and other agents such as topical 5-fluorouracil or podophyllin have been used. ${ }^{3}$ The carbon dioxide laser was effective in our patient, clearing the lesions with little discomfort and with minimal residual scarring and atrophy.

The pathogenesis of multicentric pigmented Bowen's disease is unknown but both herpes genitalis and condyloma acuminatum show a strong temporal relation to the disease, ${ }^{9}$ and virus particles with morphological similarities to herpes simplex ${ }^{1011}$ and also to human papillomavirus ${ }^{12}$ have been shown in lesions of multicentric pigmented Bowen's disease.

The occurence in our patient of antecedent carcinoma in situ of the cervix is of relevance. In an epidemiological study of 50 patients with carcinoma in situ of the vulva, Friedrick et al found an association with carcinoma in situ and three invasive carcinomas. ${ }^{13}$ From the description of $17(34 \%)$ of their patients with hyperpigmented lesions and five $(10 \%)$ with multifocal papules who experienced spontaneous regression of their disease, it would appear that many of their patients had multicentric pigmented Bowen's disease. In addition, that study showed a $30 \%$ incidence of previous or concomitant DNA viral infections (condyloma or herpes, or both) in association with vulval carcinoma in situ, which 


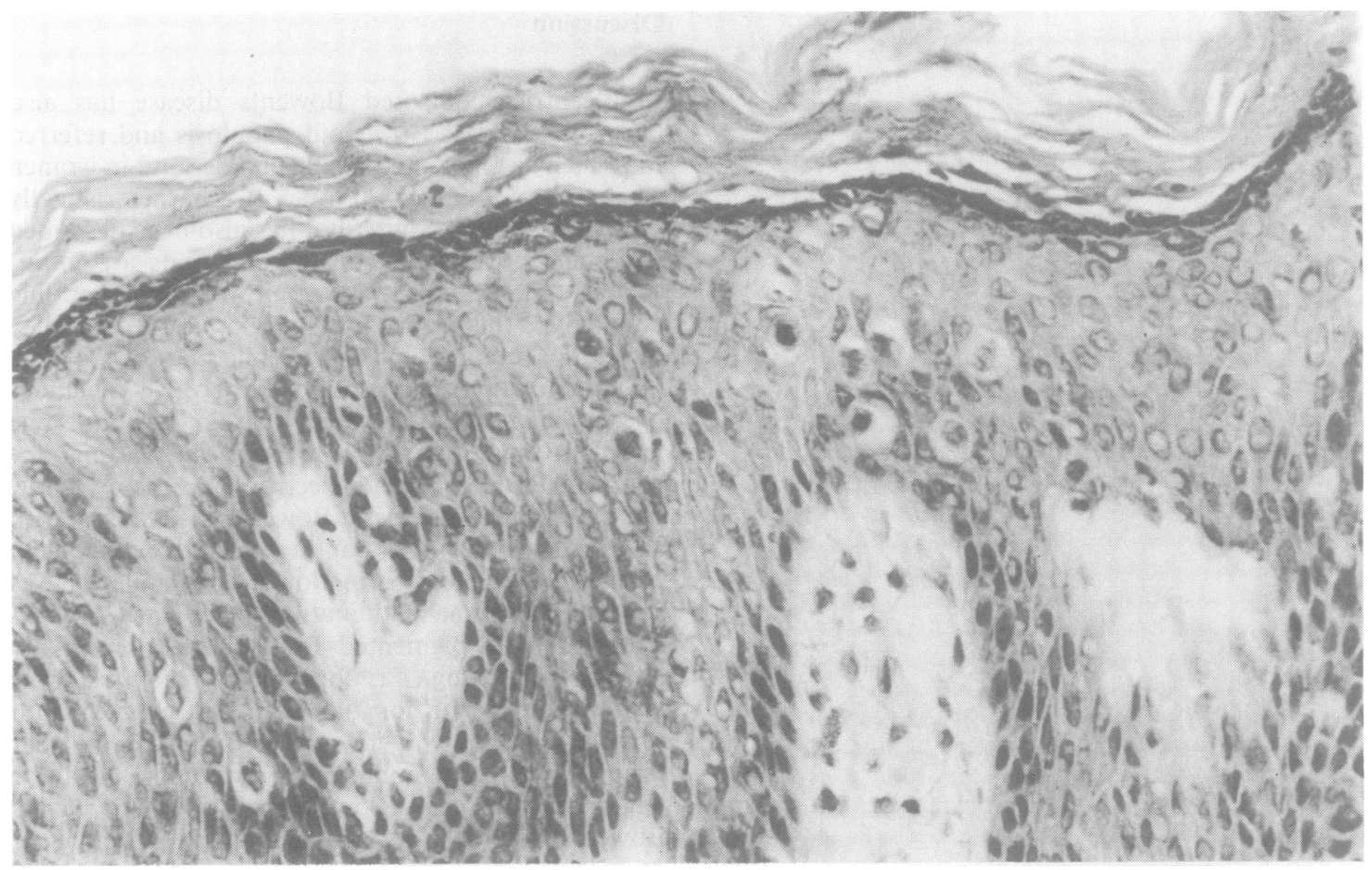

FIG 3 Section of biopsy specimen from the perianal area showing parakeratosis, acanthosis of the epidermis, individual cell keratinisation, increased basal cell pigmentation, and pigment deposits in dermal melanophages. (Haematoxylin and eosin $\times 50$.)

suggests that common pathogenic factors, probably viral, may be associated with carcinoma of the vulva and cervix. Now that multicentric pigmented Bowen's disease is recognised as clinically distinct from carcinoma in situ of the vulva, future epidemiological studies of the disease per se are required to ascertain the true incidence of associated genital malignancies.

In conclusion, it is unlikely that the appearance of multicentric pigmented Bowen's disease with carcinoma of the cervix in this patient was fortuitous. We recommend that patients with multicentric pigmented Bowen's disease should be carefully screened for coexisting carcinoma of the genital tract. Treatment with carbon dioxide laser would appear to be an effective form of treatment for this condition.

\section{References}

1. Lloyd KM. Multicentric pigmented Bowen's disease of the groin. Arch Dermatol 1970; 101:48-51.
2. Tritsch H. Bowenoide papulose, Genito-anale akanthose mit dysplasie. Dtsch Med Wochenschr 1980; 105:887-91.

3. Kimura S. Bowenoid papulosis of the genitalia. Int J Dermatol 1982; 21:432-6.

4. Skinner MS, Sternberg WH, Ichinose H, et al. Spontaneous regression of bowenoid atypia of the vulva. Obstet Gynecol 1973;42:40-6.

5. Berger BW, Hort Y. Multicentric Bowen's disease of the genitalia. Spontaneous regression of lesions. Arch Dermatol 1978; 114: 1698-9.

6. Hirai A, Inamoto $\mathbf{N}$, Harada $\mathrm{R}$, et al. So-called multicentric pigmented Bowen's disease progressing to squamous cell carcinoma. Japanese Journal of Dermatology 1979;89:380-3.

7. De Villez RL, Stevens CS. Bowenoid papules of the genitalia. A case progressing to Bowen's disease. J Am Acad Dermatol 1980; 3:149-52.

8. Mortimer PS, Sonnex TS, Dawber RPR. Cryotherapy for multicentric pigmented Bowen's disease. Clin Exp Dermatol 1983;8:319-22.

9. Wade TR Kopf AW, Ackerman AB. Bowenoid papulosis of the genitalia. Arch Dermatol 1979; 115: 306-8.

10. Friedrick EG. Reversible vulvar atypia. A case report. Obstet Gynecol 1972; 39: 173-81.

11. Stern JB. Herpes virus-induced antigens in squamous-cell carcinoma in situ of the vulva. N Engl J Med 1981;305:1586.

12. Zelickson AS, Prawer SE. Bowenoid papulosis of the penis. Demonstration of intranucleas viral-like particles. $\mathrm{Am}$ Dermatopathol 1980; 2:305-8.

13. Friedrick EG Jr, Wilkinson EJ, Fu YS. Carcinoma in situ of the vulva: a continuing challenge. Am J Obstet Gynecol 1980; 136: 830-8. 